\title{
USING PULL LOGIC OF FLOW SIMULATION IN THE PROCESS OF THE PRODUCTION PLANNING SYSTEM TRANSFORMATION
}

\author{
Łukasz Hadaś and Paweł Pawlewski \\ Faculty of Engineering Management \\ Poznan University of Technology \\ 11 Strzelecka Str. 60-965 Poznan, Poland \\ E-mail: pawel.pawlewski@put.poznan.pl
}

\section{KEYWORDS}

Shop floor control transformation, pull logic of flow, job shop, simulation.

\begin{abstract}
This article describes the problem of transformation management systems in the area of planning and shop flow control of production. The authors present practical experience of building dedicated planning system and using pull logic of flow simulation in this process. The research works were carried out in industrial engineering in complex environmental conditions of production. This was a, multi-department environment specializing in technology, characterized by multiple streams of values. The work was focused upon the transformation of the production system from the push logic of flow to the pull logic of flow and building a dedicated system based on the lean management approach.
\end{abstract}

\section{INTRODUCTION}

One of the basic decisions in the production logistics is the choice of the proper system of production planning and control. This choice directly affects the obtained level of stock and customer service and, consequently, the financial results of an enterprise.

Among methods that are worth mentioning (APICS 1995), (Encyclopedia 2000), (Krajewski Lee and Ritzman 1996) there is the traditional method of reorder point (ROP), the method of material requirements planning (MRP), or Just-in-Time method along with Kanban operational tool. The selection of the appropriate method depends on many parameters, such as complexity and variety of the offered goods, repeatability of production and market conditions, e.g. changeability and character of demand (Hadaś and Domański 2008), (Hadaś and Cyplik 2007a), (Hadas and Cyplik 2007b).

MRPII system is treated as an efficient tool for aggregated planning of production potential (Muhleman et al. 1997), (Orlicky 1975), (Wight 1984) and a source of information used in various functional areas of an enterprise. In the area of material flow it works effectively as a tool for scheduling production at the main schedule level. The possible changes in schedules and incorrect decisions as for the quantity of the production batch and supply batch may unfavorably affect the total level of stock and the use of company potential. At the shop floor level, Just-in-Time system is the most effective control tool (Ohno 1995), (Liker 2003). The Kanban tool, its basic component in the production area, makes it possible to keep the low level of work in progress (Hadas and Domański 2008), (Ohno 1995) and also to maintain the suitable rate of production in relation to the demand, by means of sufficiently implementing pull logic of flow. In particular industrial conditions, the validity of the pull concept depends upon numerous factors shown in simulations (Hopp and Spearman 2004), (Huang and Kusiak 1998), (Kim et al. 2002). In the present article, the authors show a case study based on a multidepartment enterprise with numerous streams of values and a wide assortment manufactured in the technological production structure. A special emphasis is put upon work in progress, in the context of customer service and resistance to typical disturbances related to failure frequency of machines.

\section{DIRECTION OF PRODUCTION SYSTEM TRANSFORMATION}

\section{Production Environment Characteristics}

Works on the production planning and shop floor control system were started by looking at the current functioning mode of the enterprise. This is a traditional enterprise, with a hierarchical and centralized planning structure, supported by MRP II / ERP system. Longterm planning (1 year) involves drawing up annual forecasts, intended to verify income and expenses and roughly balance machine and worker production capacity. In medium-term planning (1 - 2 months) production and supply schedules are prepared based on sales plans and confirmed orders. In short-term planning production, launch orders are sent to the foundry (a division where the production process is initiated). Orders are "pushed" through subsequent levels (the "push" logic) up to the assembly (product ready for marketing) or processing level (orders to partners in the supply chain). Machine workload plans are rough and workstations are allocated according to the technical specification. The analysis of planning and shop floor control revealed a number of problems in short and medium-term planning: 
- low level of plan integration, both vertical (management board - managers) and horizontal (supply - production),

- low level of MRPII/ERP implementation (ranked as $\mathrm{C}$ in ABCD checklist),

- poor planning discipline (no explicit processes).

In short-term planning and current production control the following observations were made:

- no total value stream vision,

- frequent conflicts about resources,

- chaotic "spaghetti" flow,

- waste of large batches,

- changeability of performance priorities.

The total image of the planning system shows the enterprise as an organization with poor management decisions (no holistic view), significant decisionmaking inertia (many management levels) and local optimization activities (production unit level), adversely affecting Work-In-Progress (WIP) and the logistics service level.

\section{Tailored MRP/JIT (Pull) Planning System}

Changing the enterprise planning system involved:

- diagnosing organizational conditions and opportunities to shape them,

- formulating planning principles based on the "Best Practice" analysis,

MRP/JIT frame integration project based on the "Lean Production" path.

In the first step, the enterprise organizational conditions were identified (see section 4.1); areas for potential improvement were discussed. Long-established relations with customers and market characteristics proved to be of particular importance (e.g. "end-ofmonth" syndrome and its influence on the planning method). In the next step, planning principles were formulated for the enterprise by reviewing the "Best Practice" in logistics and supply chain management. Key conclusions are as follows:

- the "pull" planning enhances greater flow control in process cells,

- information on demand in the whole process chain should be shared upon arising at any chain link,

- decoupling points should be located based on market demands (CTLT and demand characteristics).

These were the chief principles applied in creating a dedicated planning system. Transformation involved MRP II planning logic (unsatisfactory) and "push" flow logic (Fig. 1).

At this point MRPII system implementation status was identified as low (ranked $\mathrm{C}$ in the $\mathrm{ABCD}$ Checklist); hence the decision to use the application for order servicing and material requirements planning, in line with the MRP logic. The long-term potential was balanced by the integrated Sales and Operation Planning. S\&OP took over the role of MRPII and supports the decisions in financial liquidity, balancing human and machine resources and planning the supply function.

On the performance level, the main objective was to transform the push logic into the pull logic.

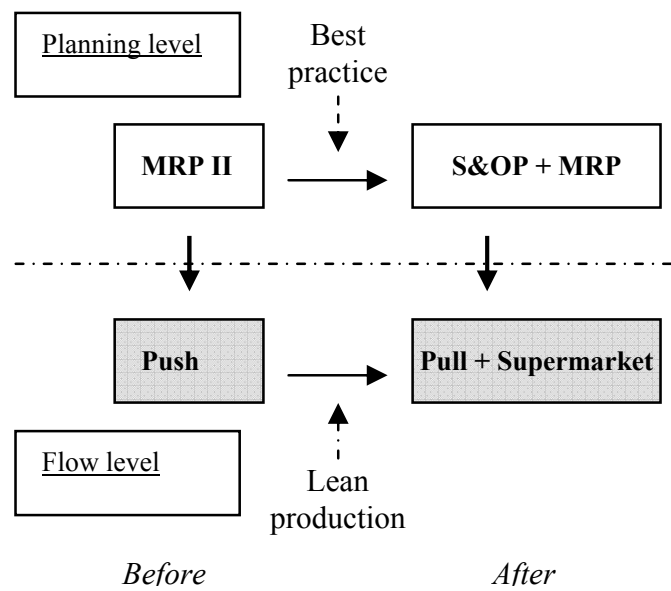

Figures 1: The direction of transformation of the production planning system (Source: own study)

So far, production orders went to the beginning of the production line and were launched in the lead time and with the required time buffer. Shifting to the pull planning logic required that production be planned and launched based on demand in subsequent links in the process (and end customer). To this end, the planning was redefined (Fig. 2) in the enterprise planning system of and optimum decoupling points were fixed for each group of finished goods. Next, the planning system on the enterprise level (S\&OP) was linked with the planning system on the level of individual divisions, thus creating detailed procedures and instructions.

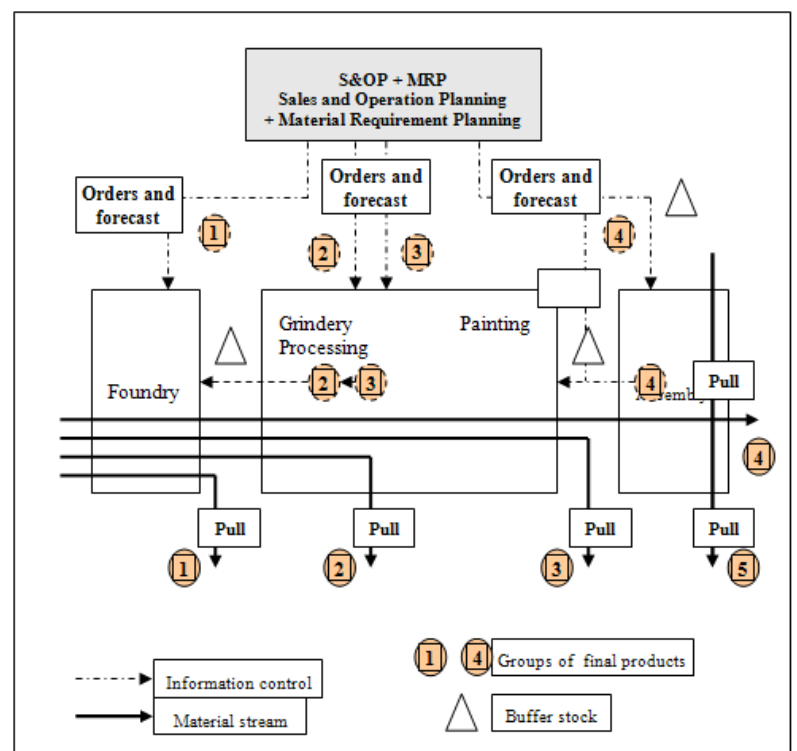

Figures 2: The logic of planning (planning input) in the "pull" system of with the aggregate sales and operation planning (Source: own study) 


\section{SIMULATION OF PULL LOGIC FLOW AND ITS ROLE IN THE TRANSFORMATION PROCESS}

\section{Context and Aim of the Simulation}

The implementation of the concept of flow according to flow logic in the conditions of an operating business is not an easy task. Both the board of the company and middle-level managers were sceptical as for the key issue, i.e. filling the production system with the required works in progress and interfacial buffers (between the main phases of the production process). Since the high works in progress already existed in the system, they were identified only with problems. For example, an average batch of goods was manufactured within three weeks, while according to production times, 2 or 3 days would be enough.

Such a situation results mainly from the lack of synchronization of the particular stages of production and the applied logic of large batches that generate the so called 'remainders'. An excessive accumulation of stocks in the production process was also related with the lack of an effective mechanism for their level control because the settlements of accounts were made in monthly cycles based on inter-department warehouse stocks and ready products.

In these circumstances the aim of the simulation was to show to the managers that, in the production conditions of a given company, the transformation from push logic of flow into pull logic is an efficient solution that would reduce the level of works in progress without deteriorating the level of customer service.

\section{Construction of the Simulation Model and Its Validation}

The mapping of the production process in production lines (flow shop) is a relatively easy task. Owing to the great similarity of operation times and unitary flow through production stands, we observe a typical 'near to one piece flow' with no recurrences, the so called looping or bottlenecks. Both the level of works in progress and the length of the production cycle (lead time) are easy to estimate.

In the analyzed case, however, the conditions are more complex. The production system is made of machines grouped according to technological specialization. The group of processed details is characterized by technological and organizational similarity at the level appropriate to the job shop $(0.5-0.65)$. The production system is unbalanced because of various unit times and preparation-termination times, as well as various duties of machines that result from technological operations addressed to them and from the so called looping characteristic to a production unit of the job shop type.

\section{Assumption for Simulation.}

Constant parameters:

- unbalanced production system with material flow of the 'job shop' type (with unbalanced load and looping of flow),
- fixed production programmed (representative of typical load),

- fixed production technology.

Variable parameters:

- push or pull logic of flow,

- quantity of transport batches,

- size of production buffers,

- level of production disturbances (machinery breakdowns).

Owing to the number of machines (about 50) and the manufactured goods (about 500), only one stream of values (family of products) was selected for the simulation along with the dedicated group of machines. In order to validate the model in terms of mapping, a series of simulations were made according to the assumed sequence of changes in flow parameters. The aim of the simulations was to estimate the usability of the tool as an instrument for investigating multi-variant logic of the production flow, and the efficiency of the performed correction activities (as for the size of buffers) in the conditions of production disturbances.

The series of simulations were performed according to the following schedule:

- comparison of push and pull logic,

- change of parameters (size of buffers and batches) for the push and pull logic,

- comparison of push and pull logic in terms of sensitivity to disturbances, such as machine breakdowns and damages of processed goods,

- change in flow parameters (size of buffers) in order to stabilize the production system (increasing its potential as for compensation for disturbances).

The obtained results were next used to estimate the validity of the production system mapping and its behavior in the variable simulation parameters.

\section{Results of Simulation and their Interpretation for the Sake of Implementation Process}

Considering the huge number of obtained reports, the paper presents fragmentary results. The total scope of research included the period of production program implementation that amounted from about 1000 up to 5232 working hours, depending on the intensity of material flow. For the assumed available standard hours relating to three working shifts from Monday to Friday, this is the period of 11 months.

The analyzed results are throughput per hour and work in progress; the analyses are made for particular details, as well as their total value for the whole production stream. The results provide basic information about the intensity of material flow in the particular reporting periods of one workday. The results show that the push logic of flow requires higher level of work in progress than the pull logic (see: Fig. 3 and 4). 


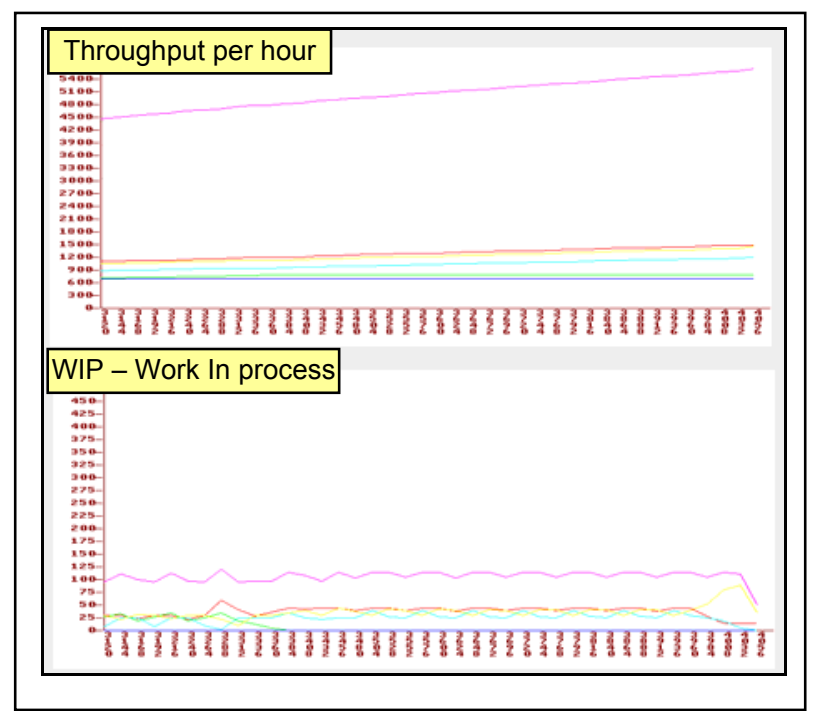

Figures 3: Results of PUSH simulation (part)

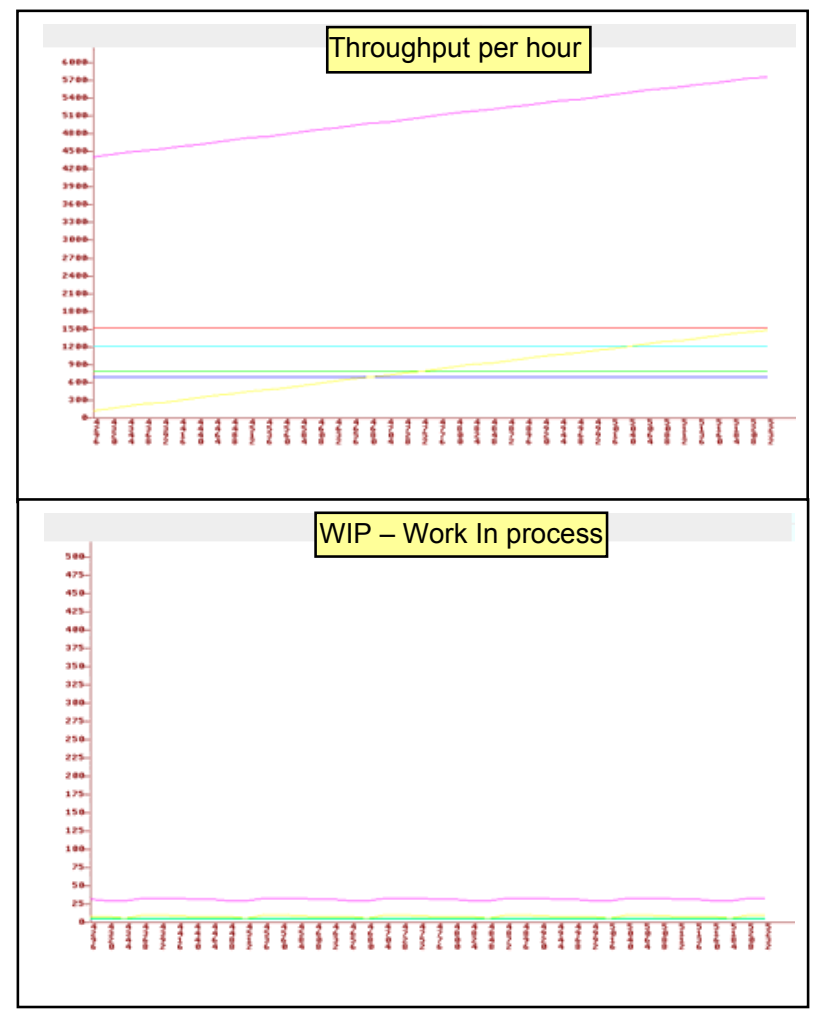

Figures 4: Results of PULL simulation (part).

The detailed analysis of the particular assortments downfall shows that the push logic represents production to be put in a warehouse according to the assumed production plan. The control of the state of buffers shows that what we observe is the typical 'pushing' of works through the production system of the enterprise. However, the analysis of the particular assortments downfall for the pull logic shows, that the production reacts to the customer's demand with the mechanism of cascade-like pulling (stepping backwards) starting from the bottom of the value stream. The analysis of the state of buffers shows that, as assumed in the experiment, we attain the stage of buffer filling and the stage of replenishing (local control according to the loop, preceding stand - subsequent stand).

Simulations beyond push and pull logic were supposed to examine the behavior of the created models in the situation of production disturbances, such as machine breakdowns and defects of the processed goods resulting from the breakdowns. In the experiments assumptions were made as for the probability distribution of the disturbances and an average time of repairs. In order to check the validity of the models, six series of simulations were made for each logic of flow (push and pull) according to the growing number of breakdowns (the article is restricted to presenting only representative fragments of results). As the occurrence of breakdowns is of probabilistic character (within the applied probability distribution), the time of breakdowns occurrence as well as their number slightly fluctuate for particular simulations.

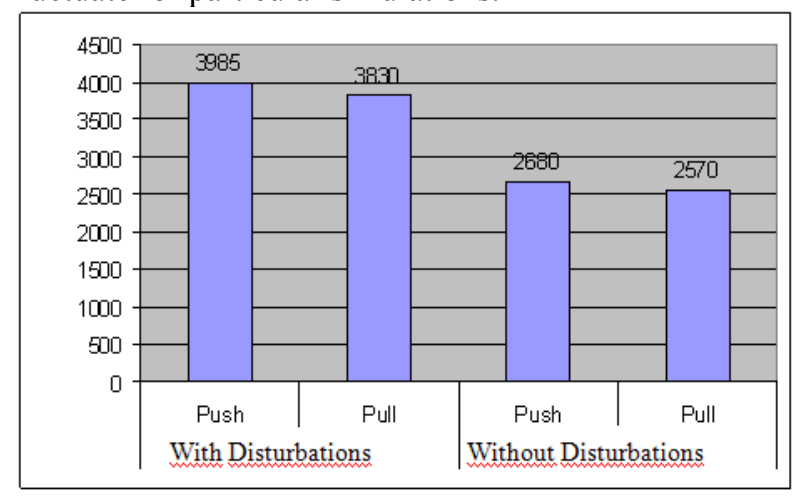

Figures 5: Effect of the process disturbances upon the amount of production made for the mapped PUSH and PULL logic in the selected period (Source: the author's study)

The conducted simulations show both the effect of occurrence and scale of disturbances upon the amount of production made for the mapped push and pull logic. Figure 5 presents slightly better results for the production made for the push logic of flow, and its slightly higher resistance to production disturbances. The differences in the results are not significant (below $5 \%$ ) for the industrial practices; yet, they show that in case pull simulation, the larger stock of work in progress acts as a universal compensator of disturbances. The comparative analysis (see: Fig. 6), taking into consideration the increase of disturbances, makes it possible to evaluate the relative 'resistance' of the mapped system to disturbances with the given forces and occurrence characteristics for the both analyzed logics of flow.

The results confirm that the production system of the push type shows a greater ability to buffer disturbances than that of the pull type. Nevertheless, earlier results show that it happens at the cost of much higher level of work in progress. 


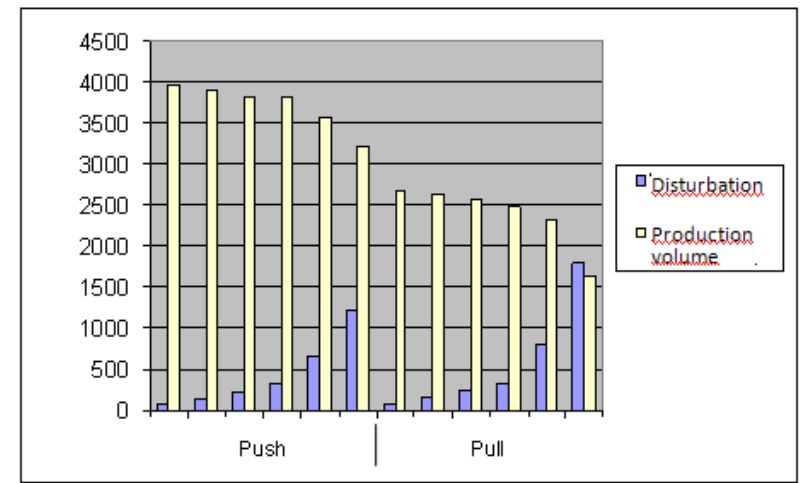

Figures 6: Effect of the scale of the process disturbances upon the amount of production made for the mapped

PUSH and PULL logic in the selected period.

\section{CONCLUSIONS AND FURTHER RESEARCH}

In the course of the investigations upon mapping the logics of flow, the implementation of the pull concept caused the biggest problems. In the industrial practice, the system is expected to be characterized by the simplicity of operation based on decentralized automatic steering. In the practice of simulation, the created algorithms of the pull mechanism functioning required a few significant corrections (these results will soon be published). Therefore, the practical observations of the authors are confirmed: pull logic is difficult to map in computer simulations.

Another important aspect was the mapping of looping characteristic of job shops with technological specialization. The mapping was crucial since it directly reflected the investigated production conditions. In the course of works on mapping the mechanisms of looping, the researchers identified a strong correlation between the size of buffers and the size of material flows 'serviced' by them, and a peculiar feedback effect. This effect as well its influence upon lengthening the production cycle and level of work in progress will be subjected to further investigations.

From the business point of view, in connection with the transformation of the planning logic of an enterprise, the result of simulation confirmed the 'reactive nature' of the solutions based on pull logic in the conditions of leveling production plan. The results emphasize the need for precise management of the interfacial buffer size in order to avoid massive increase in work in progress or decrease in the logistics level of service. The obtained conclusions were used to design operational algorithms of planning and control system.

\section{REFERENCES}

APICS. 1995. "American Production and Inventory Control Society Dictionary", VIII-th edition, American Production and Control Society, Inc., Falls Church, VA.

"Encyclopedia of Production and Manufacturing Management". 2000. Kluwer Academic Publisher, Boston/Dordrecht/London.

Hadaś Ł. and Domański R. 2008. "Mechanizmy kontroli poziomu robót $\mathrm{w}$ toku $\mathrm{w}$ systemach produkcyjnych $\mathrm{wg}$ koncepcji Lean Management i Theory of Constraints", Logistyka 2/2008, CD, 87.

Hadaś Ł. and Cyplik P. 2007. "Analiza porównawcza logiki przepływu „Push”, „Pull”, „Pull/Push” w obszarze produkcji - wyniki badań”. Logistyka nr 5/2007,. 43-47

Hadaś Ł. and Cyplik P. 2007. "Środowisko produkcyjne a wybór systemów planowania i sterowania produkcją". Logistyka $\mathrm{nr}$ 6/2007

Hopp W. J. and Spearman M. L. 2004. "To pull or not to pull: What is the question?" Manufacturing and Service Operations Management, 6(2), 133-148.

Huang C.C. and Kusiak A. 1998. "Manufacturing control with a push-pull approach". Internation Journal of Production Research, 36(1), 251-257.

Kim K.; Chhajed D.; Udatta S. and Palekar A. 2002. "Comparative study of the performance of push and pull systems in the presence of emergency orders". International Journal of Production Research, 40(7) 1627-1646.

Krajewski Lee J. and Ritzman Larry P. 1996. Operations Management. Strategy and Analysis, Fourth Edition, Addison-Wesley Publishing Company.

Liker J. K. 2003. The Toyota Way: 14 Management Principles from the World's Greatest Manufacturer. McGraw-Hill.

Muhlemann A.P.; Oakland J.S. and Lockyer K.G. 1997. Zarzqdzanie, Produkcja i Ustugi, PWN, Warszawa.

Ohno T. 1995. Toyota Production System: Beyond Largescale Production. Productivity Press Inc.

Orlicky J. 1975. Material Requirements Planning. Mc Graw Hill Book Company, New York.

Wight O. 1984. Manufacturing Resorces Planinng. Oliver Wight Limited Publications, Essex Junction, Vermont.

\section{AUTHOR BIOGRAPHIES}

LUKASZ HADAS works as an Assistant Professor at the Department of Engineering Management, Poznan University of Technology. Specializes in logistics and procurement and production organization and shop floor control of production processes. Author of about 80 scientific publications in this thematic area, both in national and foreign journals. Their relationships with business practice as a consultant building projects reorganization of production systems in the creation of dedicated solutions including hybrid MRP/TOC, MRP / JIT and transformation of planning and shop floor control system from the logic of the push to pull. His email address is lukasz.hadaseput.poznan.pl

PAWEL PAWLEWSKI works as an Assistant Professor at the Department of Engineering Management, Poznan University of Technology. He holds a PhD in Mechanical Engineering, specialization "organization of production systems" from the Poznan University of Technology. His research interests include organization of manufacturing systems, monitoring of operations management, reengineering and IT application for logistics. Author of about 100 scientific publications. From 2011 he is managing director of SOCILAPP - Simulation and Optimization Center in Logistics and Production Processes His e-mail address is pawel.pawlewski@put.poznan.pl 